\title{
Efficacy of Thermally Conditioned Sisal FRP Composite on the Shear Characteristics of Reinforced Concrete Beams
}

\author{
Tara Sen $^{1}$ and H. N. Jagannatha Reddy ${ }^{2}$ \\ ${ }^{1}$ Department of Civil Engineering, National Institute of Technology, Agartala, Barjala, Tripura (West), Jirania 799055, India \\ ${ }^{2}$ Department of Civil Engineering, Bangalore Institute of Technology, K. R. Road, V. V. Puram, Bangalore 560004, India
}

Correspondence should be addressed to Tara Sen; tarasen20@gmail.com

Received 30 May 2013; Revised 8 August 2013; Accepted 28 August 2013

Academic Editor: Hazizan Md Akil

Copyright (C) 2013 T. Sen and H. N. J. Reddy. This is an open access article distributed under the Creative Commons Attribution License, which permits unrestricted use, distribution, and reproduction in any medium, provided the original work is properly cited.

\begin{abstract}
The development of commercially viable composites based on natural resources for a wide range of applications is on the rise. Efforts include new methods of production and the utilization of natural reinforcements to make biodegradable composites with lignocellulosic fibers, for various engineering applications. In this work, thermal conditioning of woven sisal fibre was carried out, followed by the development of woven sisal fibre reinforced polymer composite system, and its tensile and flexural behaviour was characterized. It was observed that thermal conditioning improved the tensile strength and the flexural strength of the woven sisal fibre composites, which were observed to bear superior values than those in the untreated ones. Then, the efficacy of woven sisal fibre reinforced polymer composite for shear strengthening of reinforced concrete beams was evaluated using two types of techniques: full and strip wrapping techniques. Detailed analysis of the load deflection behaviour and fracture study of reinforced concrete beams strengthened with woven sisal under shearing load were carried out, and it was concluded that woven sisal FRP strengthened beams, underwent very ductile nature of failure, without any delamination or debonding of sisal FRP, and also increased the shear strength and the first crack load of the reinforced concrete beams.
\end{abstract}

\section{Introduction}

The recent developments in the application of advanced composites in the construction industry for concrete strengthening are increasing on the basis of specific requirements, national needs, and industry participation. The need for efficient strengthening techniques of existing concrete structures has resulted in research and development of composite strengthening systems. For years, civil engineers have been in search for alternatives to steels and alloys to combat the high costs of repair and maintenance of structures damaged by corrosion and heavy use. Since the 1940s, composite materials, formed by the combination of two or more distinct materials in a microscopic scale, have gained increasing popularity in the engineering field. Fiber Reinforced Polymer (FRP) is a relatively new class of composite material manufactured from fibers and resins and has proven efficient and economical for the development and repair of new and deteriorating structures in civil engineering. The mechanical properties of FRPs make them ideal for widespread applications in construction worldwide. Strengthening of reinforced concrete (RC) structures is frequently required due to inadequate maintenance, excessive loading, change in use or in code of practice, and/or exposure to adverse environmental conditions. The use of FRP composites as a replacement to steel reinforcement has proved to be a promising solution to this problem [1-5]. FRP composites possess some outstanding properties such as resistance to corrosion, good fatigue and damping resistance, high strength to weight ratio, and electromagnetic transparency. FRP has found an increasing number of applications in construction either as internal or as external reinforcement for concrete structures [6-13]. It is well known that FRP possesses a major advantage over conventional steel in reinforcing concrete structures. The fibers, typically composed of carbon or glass, provide the strength and stiffness. The matrix, commonly 
made of polyester, epoxy, or nylon, binds and protects the fibers from damage and transfers the stresses between fibers. Various researches on different reinforcements in the form of fibers, which can be suitably used for processing of FRP, are underway. One such newly developed reinforcement is the use of natural fibers in the processing of FRP [14-17]. Similarly, common matrix materials include epoxy, phenolic, polyester, polyurethane, polyetheretherketone (PEEK), and vinyl ester. Among these resin materials, PEEK is most widely used. Epoxy, which has higher adhesion and less shrinkage than PEEK, comes in second for its high cost.

In the last decade, there has been a fast development in the area of composites reinforced with vegetable fibers for processing of FRP. The cellulosic fibers have a lot of important features such as low cost, low density, specific resistance, biological degradability, $\mathrm{CO}_{2}$ neutrality, renewability, good mechanical properties, nontoxicity and can be easily modified by a chemical agent. Sisal (Agave sisalana), is a good example of such fibers. It was planted in India in the earliest of the civilization, and in those days it was used for making ropes. Nowadays, Sisal is mainly cultivated in Madhya Pradesh, Tamil Nadu, Kerela, Orissa, and also in Goa. India is also becoming one of the largest producers of natural fiber like sisal after Brazil and Africa. The sisal fibers, as well as most of the other lignocellulosic fibers are constituted of cellulose (65.8\%), hemicellulose (12\%), lignin (9.9\%), pectin (0.8\%), wax (0.3\%), and water soluble compounds. Cellulose, which awards the mechanical properties of the complete natural fiber, is ordered in microfibrils enclosed by the other two main components: hemicellulose and lignin. Lignin is an aromatic biopolymer, an integral cell wall constituent of all vascular plants and hemicelluloses are a large group of polysaccharides found in the primary and secondary cell walls of the plants. These three mentioned components are responsible for the physical properties of the fibers. These natural fibers can be effectively used in the manufacture of fiber reinforced polymer composites because they possess attractive physical and mechanical properties [18-21]. They impart the composite high specific stiffness and strength, a desirable fiber aspect ratio, biodegradability, they are readily available from natural sources, and more importantly they have a low cost per unit volume basis [2225]. Unlike the traditional engineering fibers, for example, glass and carbon fibers, along with mineral fillers, these lignocellulosic fibers are able to impart the composite certain benefits such as low density; less machine wear than that produced by mineral reinforcements; no health hazards; a high degree of flexibility [26-29]. One difficulty that has prevented a more extended utilization of the sisal fiber is their lack in providing good adhesion to most polymeric matrices. The hydrophilic nature of natural fibers adversely affects adhesion to a hydrophobic matrix and as a result, it may cause a loss of strength. To prevent this, the fiber surface has to be modified in order to promote adhesion. Several methods to modify the natural fiber surface have been proposed: the graft copolymerization of monomers onto the fiber surface, the use of maleic anhydride copolymers, alkyl succinic anhydride, stearic acid, and so forth. It has also been reported that the use of coupling agents such as silanes, titanates, zirconates, triazine compounds, and so forth also improve fiber-matrix adhesion and also the fiber-matrix interaction. But all these modification methods are mainly for short fiber composites, and none of these methods have given satisfactory results for the textile or woven fiber composites. The woven fiber composites behave in a completely different manner from short fiber composites. Any sort of chemical modification of woven or textile composites has resulted in lowering of tensile strength and flexural strength [30-34]. The major contribution to strength in textile composites is the alignment of yarns in warp and weft direction. Chemical treatment results in the partial unwinding of yarns (as hemicellulose dissolves off) and hence the alignment gets antagonized. This results in lowering of strength of the woven composites. Another reason is that as woven fibers are composed of thick strands and knots, the chemical agents cannot penetrate into the fabric and therefore the interfacial properties between the woven fibers and the matrix does not get enhanced. There has been recent, huge development and research on textile structural composites, and they are finding use in various high performance applications. Thermal conditioning, which in simple words can be said as heat treatment, provides an improvisation in the mechanical properties of woven fabric or textile composites in an effective manner. Physical method of thermal treatments, of woven yarn, does not make changes on the structural composition but modify the surface properties, this influences good mechanical bonding with the matrix and ensures enhanced composite properties [30-34].

\section{Materials and Methodology for Composite Characterization}

2.1. Materials. The sisal fabric with natural rubber backing was collected from Extra Weave Private Ltd., Cherthala, Kerala, India. The natural fibers of sisal could be used to reinforce both thermosetting and thermoplastic matrices. Thermosetting resins, such as epoxy, polyester, polyurethane, and phenolic are commonly used today in natural fiber composites, in which composites require high performance applications. They provide sufficient mechanical properties, in particular, stiffness and strength, at acceptably low price levels. Here, we have used MBrace saturant resin, which consisted of two parts, part A and part B. Part A was the epoxy resin which belonged to the group of bisphenol A. Part B was hardener which belonged to the group of polyamine, chemically belonging to the epoxide family. Both part A epoxy resin and part $\mathrm{B}$ hardener was used as the matrix material together, in combination. The epoxy resin and the hardener were both obtained from BASF Construction Chemicals Chandivali, Andheri East, Mumbai, India. MBrace saturant resin was easy to apply, $100 \%$ solid material that permitted adhesion of a lightweight sheet, within the MBrace composite strengthening system. The resin produced a high performance composite system to be used for external structural repair or upgrade application. All other chemicals used for the fabrication and for the concrete strengthening purpose, such as concresive 2200 and MBrace primer, were all obtained from BASF Construction Chemicals Chandivali, 
Andheri East, Mumbai, India. MBrace primer was a low viscosity, $100 \%$ solid, polyamine cured epoxy. The primer was the first applied component of the MBrace system, it was used so as to penetrate the pore structure of cementitious substrates in order to provide a high bond base coat for the MBrace System.

\subsection{Thermal Conditioning and Fabrication of Woven Sisal} FRP Composites. The process of thermal conditioning could be achieved by either using convection currents or by using microwave radiation. Here, it was achieved by using thermostatically controlled oven, which uses convection currents for thermal conditioning, rather than using microwave radiation. There have been several disadvantages of using microwave radiation for thermal conditioning of natural fibers. It was to be kept in mind that the application of these woven sisal fibers in the form of woven fiber FRP composite was sought for in structural elements, in an effective manner, hence, we would be dealing with large quantities of such materials for real life use, if so established. Hence, this ruled out microwave radiation conditioning of the fibers, as it would lead to huge energy consumption as well would generate huge production costs. And since we were looking for cheap, biodegradable, sustainable material, with low production cost, but also with improved properties, which could be suitably compared with glass FRP composite, so that the utilization of natural FRP could be visualized worldwide, hence, cheaper treatments methods were sought for. Microwave radiation treatment is for lowflow capacity $\mathrm{R}$ and $\mathrm{D}$ applications and this makes them suitable for small-scale installations only. Convection heating is for fast product expansion and production, such as thermal treatment of lignocellulosic fibers for large scale natural FRP production. The main difference between conventional heating and microwave heating was the heating mechanism. While conventional techniques heated a surface, the microwaves heated the whole volume of the treated object. During the conventional heating, the heat was generated outside the treated product and conveyed by conduction or convection. Hence, the surface would get heated at first and afterwards the heat flowed towards the inside, which always remained colder than the outer surface. In this method of conventional heating, since heat was transferred molecule by molecule from the outside to the inside, hence, this process displayed the disadvantage of overheating the outer surface of the material; but it was quite clear that the advantages of convection heating outweighed the disadvantages and most of the shortcomings, as a measure for the treatment of natural woven fibers. Figure 1 gives the pictorial representation of the thermostatically controlled oven for convection heating and the mechanism of convection heating. The mechanical treatment in the form of thermal conditioning was carried out in the following manner: sisal fabric mats were cut into the size as required for flexural strength test as per ISO 14125:1998 and tensile strength test as per ISO 527$4: 1997(\mathrm{E})$. Some of the samples of these woven fiber mats were then placed into the thermo-statically controlled oven at $80^{\circ} \mathrm{C}$ for 48 hours. After 48 hours, it was removed from the oven, and used for composite fabrication. The rest of the samples were left as they are, for composite fabrication, that is, the rest of the samples were not subjected to thermal conditioning, in other words these were the samples which were untreated and is referred to here as control samples. Thereafter, all the samples, which consisted of both thermally conditioned woven sisal fiber mats and untreated or raw or control samples of woven sisal fiber mats, which were not subjected to thermal conditioning, were all used for fiber reinforced polymer composite fabrication, so that a comparative study to deduce effect of thermal conditioning could be carried out. For the composite fabrication, a plastic bit mould of suitable dimension was used for casting the fabric composite sheets. The usual hand lay-up technique was used for the preparation of the samples. A calculated amount of epoxy resin and hardener ratio of $10: 4$ by weight was thoroughly mixed with gentle stirring to minimize air entrapment. For quick and easy removal of composite sheets, a mould releasing agent was used. Electrical insulating paper was put underneath the plastic bit mould and mould release agent, that is, either poly vinyl alcohol or silicone grease was applied at the inner surface of the mould. After keeping the mould on the insulating sheet, a thin layer ( $\approx 2 \mathrm{~mm}$ thickness) of mixture of epoxy and hardener was poured. Then, the fabric mats were separately distributed on the mixture on different moulds. The remaining mixture was then poured into the mould on top of the fabric mats. Care was taken to avoid formation of air bubbles. Pressure was then applied from the top (on top of the electrical insulating paper, placed above the FRP), with the help of flat weights, so that no air bubbles remained in the epoxy-fiber reinforced polymer mix. It was ensured that no air bubbles remained in the FRP, and then the pressure was withdrawn. Any arbitrary pressure could be applied by using suitable flat iron weights (e.g., steel I beams or flats, etc.), so that the pressure gets uniformly distributed, and no air bubbles exist in the composite. It was allowed to cure at room temperature for $48 \mathrm{hrs}$. After $48 \mathrm{hrs}$ the samples were taken out from the mould and kept in an air tight container for further experimentation.

2.3. Mechanical Testing of Woven Sisal FRP Composite. Two mechanical tests were performed for all the three samples of woven sisal fiber composites, the two tests include tensile strength test, and flexural strength test. All the samples of the thermally conditioned sisal fibers, which was fabricated into composites and also the untreated or raw woven sisal fibers, which was fabricated into composites, were both subjected to these mentioned two tests, so as to obtain a comparison in their mechanical properties in order to evaluate the effect of thermal conditioning. During the tensile test, a uniaxial load was applied through both the ends of the specimen, using suitable jaws as an attachment to the UTM. The tensile test was performed in the universal testing machine (UTM) which in this case was HEICO digital universal testing machine and results were obtained digitally with the digital data acquisition system, which aided us to calculate the tensile strength of composite samples. The tensile strength test for woven sisal FRP composites, were done in accordance to ISO 527-4:1997(E), as sisal falls under the category of Type- 2 materials. Figure 2 shows the tensile 


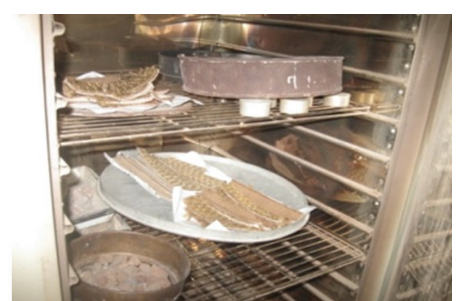

(a)

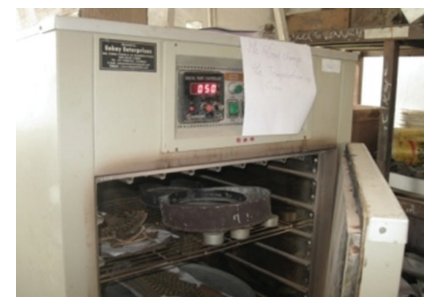

(b)

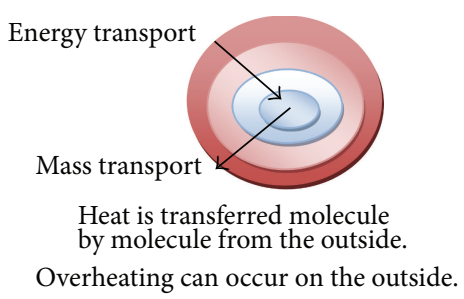

(c)

FIGURE 1: (a) samples in oven for thermal conditioning; (b) thermostatically controlled oven; (c) mechanism of convection heating.

loading as well as the tensile fractures in the composite samples and also the sample dimensions for the tensile test. Sisal FRP composites displayed only diagonal type of fracture. The diagonal fracture failure mode is an accepted mode of tensile fracture in accordance to ISO 527-4:1997(E). The tensile testing of the composite was followed by flexural testing. The flexural strength of a composite is a 3-point bend test, which generally promotes failure by interlaminar shear. This test was conducted as per ISO 14125:1998 standard using a load cell of high sensitivity. The flexural loading arrangement as well as the flexural fracture is shown in Figure 3. Since sisal belonged to Class II type material, hence, all the restrictions of the specimen dimensions for flexural testing was followed for class II material, as per the code ISO 14125:1998. The flexural failure of all the specimens of the FRP composites showed a single line fracture (perpendicular to the plane of the composite direction). The tensile and the flexural strength test were carried out at a cross head speed of $1 \mathrm{~mm} / \mathrm{min}$, and this cross head speed was maintained throughout the testing. Table 1 gives the value of the flexural strength and tensile strength of woven sisal FRP composites and also describes the dimensions of various parameters used for tensile and flexural testing of the composite samples.

\subsection{Effect of Thermal Conditioning on the Mechanical Proper-} ties of Woven Sisal Fibers. The effect of thermal conditioning or heat treatment, which was at elevated temperature, could be described as a threefold effect on the cellulosic fibers

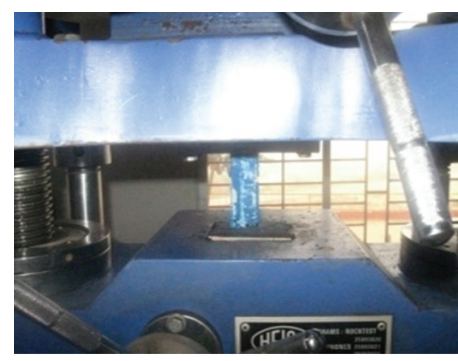

(a)

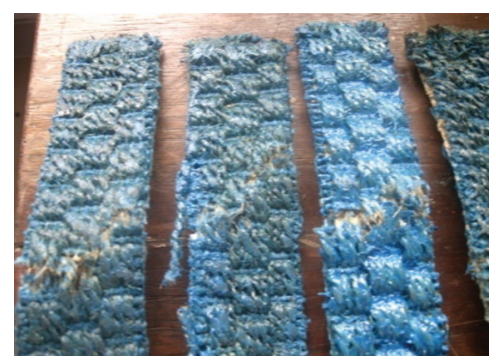

(b)

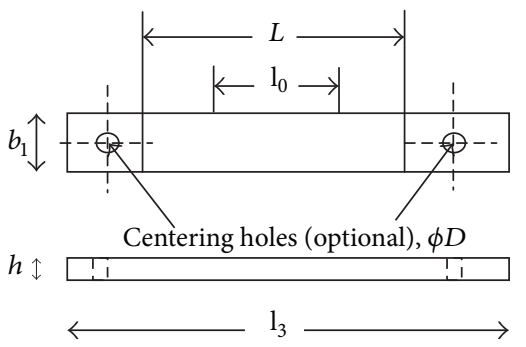

(c)

FIgURE 2: (a) Tensile testing; (b) tensile fracture samples of woven sisal FRP composite; (c) dimensions of the sample for tensile testing.

of sisal. Firstly, the modification of cellulosic structure by enhanced cross-linking, then secondly, increased amount of crystallinity in the fibers, and thirdly, by de-moisturization, which improved the adhesion between the fibers and the natural rubber backing of the fabric. High temperature in general accelerated as well as activated chemical reactions, in cellulosic materials, such as natural fibers of sisal, which consisted of $65.8 \%$ cellulose, it lead to the formation of radicals, which in turn directed to several other reactions. Also, at elevated temperatures, there was cross linking of cellulose, which reduced the swellability of the lignocellulosic fibers. This reaction was homogeneous with the temperature range of $70^{\circ} \mathrm{C}$ to $180^{\circ} \mathrm{C}$. The natural fibers generally undergo degradation at about $200^{\circ} \mathrm{C}$. Structural constituents of the fiber (cellulose, hemicelluloses, lignin, etc.) were sensitive to the different range of temperatures. It was seen that lignin started degrading at a temperature around $200^{\circ} \mathrm{C}$ and hemicelluloses and cellulosic constituents started degrading at higher temperatures. Hence, one must be careful enough to maintain the maximum temperature for thermal conditioning below $200^{\circ} \mathrm{C}$, since vegetable fibers undergo degradation at higher temperatures above $200^{\circ} \mathrm{C}$. In the presence of oxidation, cross-linking of cellulose was enhanced by formation of hemiacetal groups by the carbohydrate chains. Thermal 


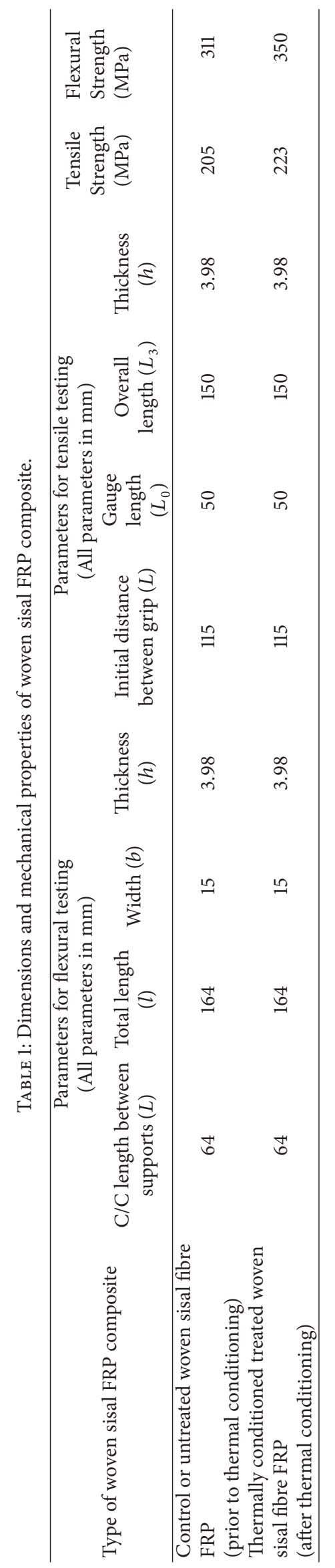




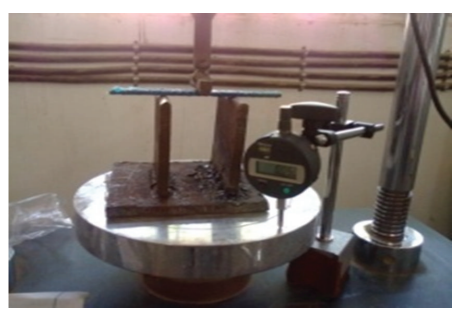

(a)

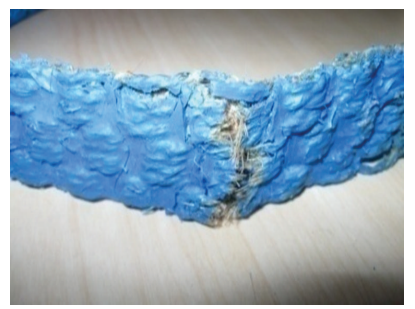

(b)

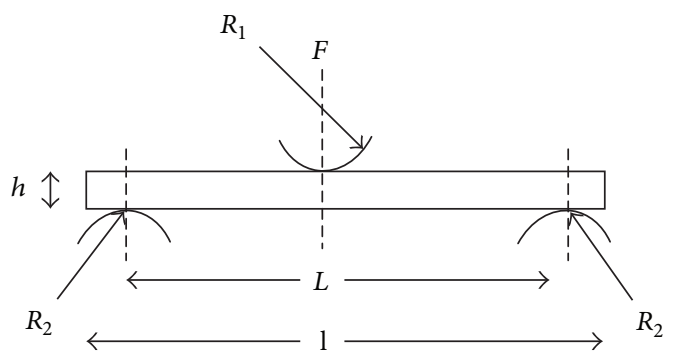

(c)

Figure 3: (a) Flexural testing (b) Flexural fracture of woven sisal FRP composite; (c) dimensions of the sample for flexural testing.

conditioning, basically a physical process, directed to the modification of the fiber surface morphology, rather than changing the fiber internal structure. Thermal conditioning also increased the crystallinity of the fibers, the crystallinity of the fibers could be attributed to the fact that upon consistent heat treatment at $80^{\circ} \mathrm{C}$, for 48 hours, the crystallinity of cellulose increased due to the rearrangement of molecular structure at elevated temperatures, and it also resulted in moisture loss of the fabric, thereby, enhancing the extent of the bonding between fabric and the natural rubber backing of the fabric. As we know that de-moisturization plays a vital role in enhancing mechanical properties, hence, the overall mechanical properties of composites prepared with thermally conditioned woven sisal fibers in fabric form were better than the composites prepared with untreated or the control ones, that is, those fabricated composites which were tested for their mechanical properties without thermal conditioning.

\section{Methodology for Shear Strengthening of Reinforced Concrete Beams}

This chapter evaluates the applicability of the woven sisal FRP composite as a shear strengthening material for reinforced concrete beam members. In this study, the woven sisal FRP sheets were bonded on on the surface of the RCC (reinforced cement concrete) beam specimens and the strengthened specimens were tested under a two-point bending configuration for their ultimate shear strength.

3.1. Design of Reinforced Concrete Beams. The experimental program contained three beam groups. All the beams in groups $\mathrm{A}, \mathrm{B}$, and $\mathrm{C}$ had the same reinforcement detailing, although the beam length for design is $1.3 \mathrm{~m}$, it is cast as $1.4 \mathrm{~m}$ for providing $50 \mathrm{~mm}$ clearance from both the sides at the supports. In accordance, the RCC beam design was carried out as per IS-456:2000. The entire reinforcement details, which were followed for all the three groups, have been shown in Figure 4. The beams were designed such that shear failure in the beam occurs before flexural failure. Hence, beams were strengthened in flexure, by providing additional flexural reinforcement, and it was also made sure that the beam design remains underreinforced, even after the provision of extra flexural reinforcement in the form of one main bar at the beam bottom. All the beams in groups $B$ and $C$ were utilized for evaluating the effect of shear strengthening provided by woven sisal fiber reinforced polymer composite, and beams in group $\mathrm{A}$, which was not strengthened, were used for comparative shear strength study purpose. Casting of RCC beams was carried out with the reinforcing detailing as shown in Figure 4, using cement of 53 grade, clean river sand as fine aggregates, and $12 \mathrm{~mm}$ and down sized coarse aggregates, with the conjunction of clean water, using the mix proportion by weight of cement: fine aggregate: coarse aggregate as $1: 2.07: 1.87$. along with a water cement ratio 0.5 .

3.2. Strengthening of Reinforced Concrete Beams with Woven Sisal FRP. The beams in group A were designed as controlled specimen (ConS1, ConS2), where no FRP application was carried out, the beams in group $B$ were designed to investigate the effect of full wrapping technique $90^{\circ}$ ( 3 sided U wrap), for shear strengthening provided by using sisal FRP (SS1, SS2), and the beams in group C were designed to investigate the effect of strip wrapping technique $90^{\circ}$ (3 sided U wrap) where $50 \%$ of the total area was used for strengthening, that is, $62 \mathrm{~mm}$ strips placed at $124 \mathrm{~mm} \mathrm{C/C}$ at a clear gap of $49 \mathrm{~mm}$ at the ends, for shear strengthening provided by using sisal FRP (SS3, SS4), a summary of the test beams have been shown in Table 2. The beams were prepared by grinding 3 side surfaces with the help of a grinding machine, this was done so as to roughen the three sides of the beam where FRP application would be carried out, and for roughening the beam surface ensures good boding of the composite material. After grinding, all the three side surface of the beams were cleaned with an air nozzle, and finally wiped to remove any dust or loose particles. Small surface defects in concrete were repaired and made good using concresive 2200 . Then, a coat of MBrace Primer was applied on all the three sides of the beams in group B and C. The primer coat was allowed to air cure for 8 hours. Next, Resin Part A and Hardener Part $\mathrm{B}$ of the two component MBrace saturant were mechanically premixed as per the guidelines of the BASF manufacturer for 3 minutes or until homogeneous. The property of the MBrace saturant as provided by the manufacturer is given in Table 3 . The ratio of mixing of resin and hardener followed as per 


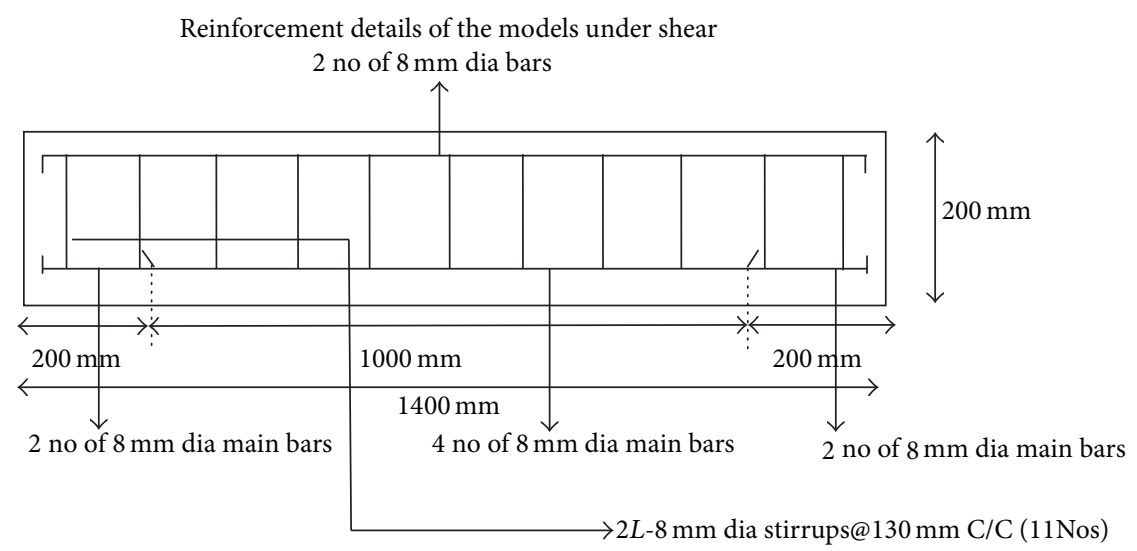

(a)

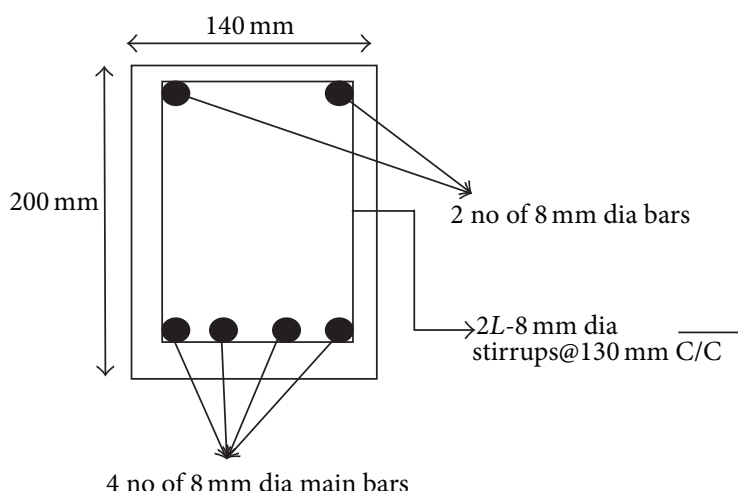

$\mathrm{C} / \mathrm{S}$ at mid-span

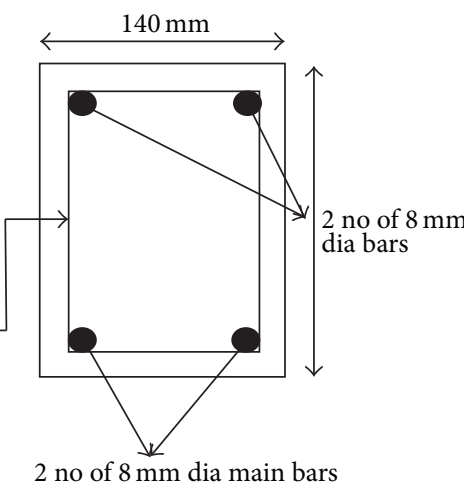

C/S at support

(b)

FIGURE 4: Reinforcement detailing of RCC beams (all sets, group A, B, and C).

TABLE 2: Summary of test beams.

\begin{tabular}{|c|c|c|c|c|c|}
\hline Beam group & Wrapping configuration & $\begin{array}{c}\text { Strengthening } \\
\text { material }\end{array}$ & $\begin{array}{c}\text { Beam } \\
\text { designation }\end{array}$ & $\begin{array}{c}\text { Type of } \\
\text { strengthening }\end{array}$ & $\begin{array}{c}\text { Strengthening } \\
\text { scheme }\end{array}$ \\
\hline Group A & $\mathrm{Nil}$ & Nil & $\begin{array}{c}\text { Control } \\
\text { specimen } \\
\text { ConS1, ConS2 }\end{array}$ & $\begin{array}{l}\text { No } \\
\text { strengthening }\end{array}$ & Nil \\
\hline Group B & Full wrapping $90^{\circ}$, single layer & Sisal FRP & SS1, SS2 & $\begin{array}{l}\text { Shear } \\
\text { strengthening } \\
\text { throughout } \\
\text { using woven } \\
\text { sisal FRP }\end{array}$ & $\begin{array}{l}\text { U-Wrap, three } \\
\text { sided wrap }\end{array}$ \\
\hline Group C & $\begin{array}{l}\text { Strip wrapping } 90^{\circ} \text {, single layer } \\
62 \mathrm{~mm} \text { strips at } 124 \mathrm{~mm} \mathrm{C} / \mathrm{C} \text { (at a clear } \\
\text { gap of } 62 \mathrm{~mm} \text { ) so as to achieve } 50 \% \text { of } \\
\text { total area strengthening, with end clear } \\
\text { gaps of } 49 \mathrm{~mm} \text {. }\end{array}$ & Sisal FRP & SS3, SS4 & $\begin{array}{l}\text { Flexural } \\
\text { strengthening } \\
\text { in strips, } \\
\text { throughout } \\
\text { using woven } \\
\text { sisal FRP }\end{array}$ & $\begin{array}{l}\text { U-Wrap, three } \\
\text { sided wrap }\end{array}$ \\
\hline
\end{tabular}

the manufacturer was $3: 1$. Then, the neatly measured and cut pieces of woven sisal fabric were applied on the beams SS1, SS2, SS3, and SS4. The composite fabric was placed on top of epoxy resin coating immediately on the respective beams and the resin was squeezed through the roving of the fabric with plastic laminating roller. It was made sure that all the fiber reinforcements are properly impregnated in the resin hardener mix. Air bubbles entrapped at the epoxy/concrete or epoxy/fabric interface were to be eliminated. All the strengthened concrete beams were cured for at least two 


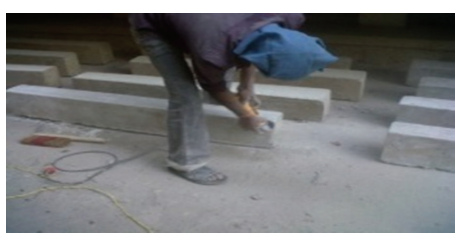

(a)

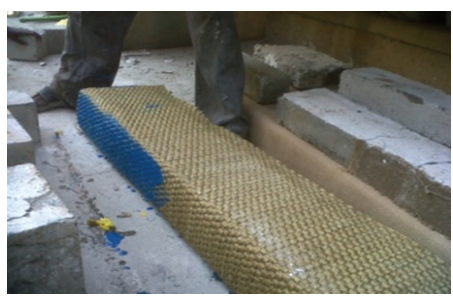

(d)

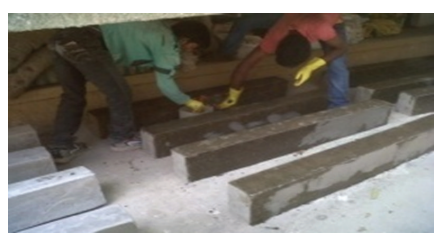

(b)

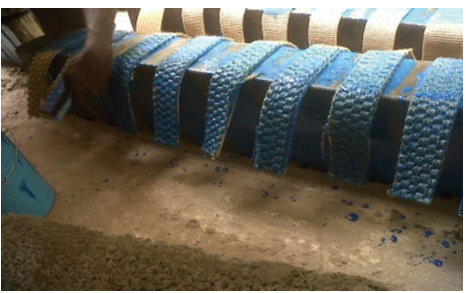

(e)

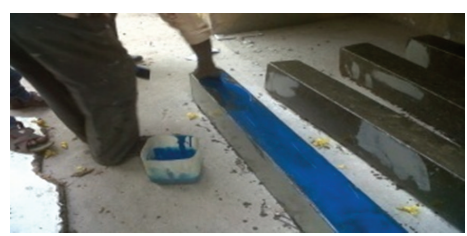

(c)

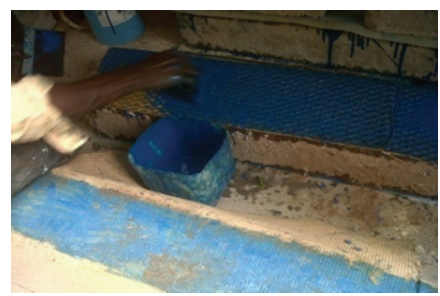

(f)

FIGURE 5: (a) surface preparation of beams by grinding; (b) primer application on beam surface; (c) application of epoxy hardener mix on the beam; (d) bonding of woven sisal (full wrap); (e) bonding of woven sisal (strip wrap); (f) final coating of epoxy hardener mix on the bonded fabric.

TABLE 3: Typical properties of MBrace saturant.

\begin{tabular}{lc}
\hline Mechanical property & MBrace saturant \\
\hline Description & 2 parts; Part A-Epoxy and Part B-Hardener \\
Density & $1.06 \mathrm{~kg} / \mathrm{Lt}$ (Mixed density) \\
Colour & Blue \\
Bond strength & $>2.5 \mathrm{~N} / \mathrm{mm}^{2}$ (Failure in concrete) \\
\hline
\end{tabular}

weeks at room temperature before the beams were tested. The entire strengthening process that is surface preparation of beams and bonding of FRP has been demonstrated in Figure 5.

3.3. Experimentation. A two-point loading system was adopted for the tests. At the end of each load increment, deflection, ultimate load, type of failure, and so forth, were carefully observed and recorded. The experimental setup under the two-point loading system is as shown in the Figures 6(a) and 6(b). Deflection behavior under the load and at the centre of the beam and the ultimate shear strength of all the beams were noted.

\section{Results and Discussions}

The mechanical characterizations of the woven sisal FRP composites in terms of tensile and flexural behavior are hereby presented in Figure 7. Figures 7(a) and 7(b) depict the comparative tensile and flexural behavior of the thermally treated and untreated or control woven sisal FRP composites. It was clearly observed that thermal treatment or conditioning improved the tensile as well as the flexural strength of woven sisal FRP composite in comparison to untreated or control woven sisal FRP composites. This thermally conditioned woven sisal was then used for strengthening of reinforced concrete beams in the form of thermally conditioned woven sisal FRP bonded to the reinforced concrete beams,

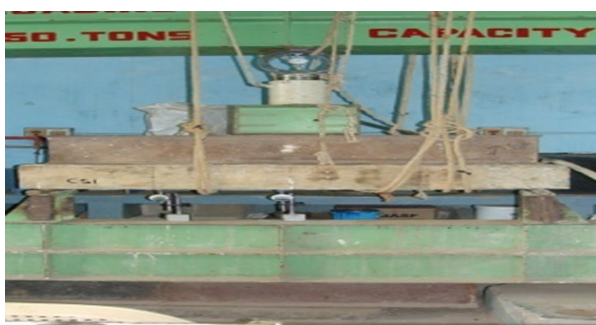

(a)

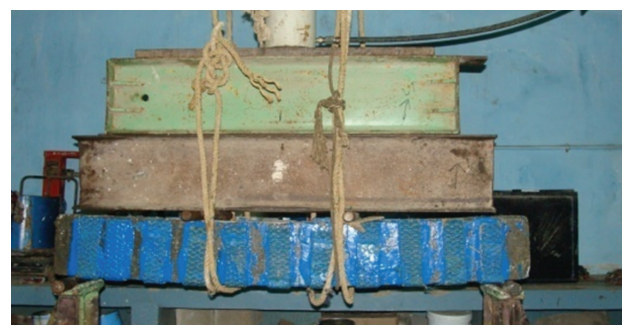

(b)

FIGURE 6: (a) two-point loading system on a 50 ton loading frame; (b) loading on strip wrapped beam with woven sisal FRP.

and they were tested in order to evaluate their efficacy in improving the ultimate shear strength of reinforced concrete beams. Different types of modes of failure have been observed in the experiments of RCC beams strengthened in shear by sisal FRPs. All the three sets of beams in group $\mathrm{A}, \mathrm{B}$, and $C$ were tested to find out their ultimate shear strength capacity. The ultimate load carrying capacity, that is, the ultimate shear strength of all the beams along with the nature of failure and deflections are given in Table 4. The fractured beam specimens belonging to various groups are as shown in Figure 8. Also, the load deflection curves for strengthened beams along with control specimens are as shown in Figure 9, and the comparison of the ultimate load carrying capacity and the first crack load are as shown in Figure 10. The three 


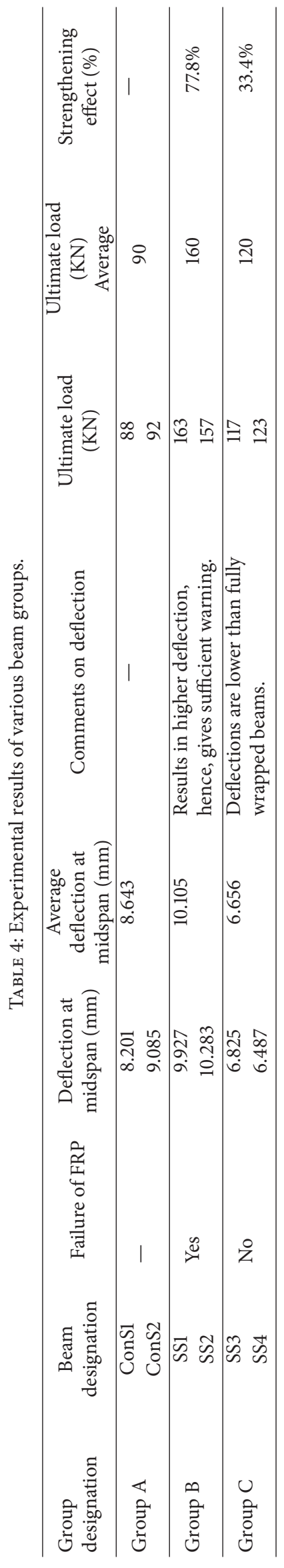



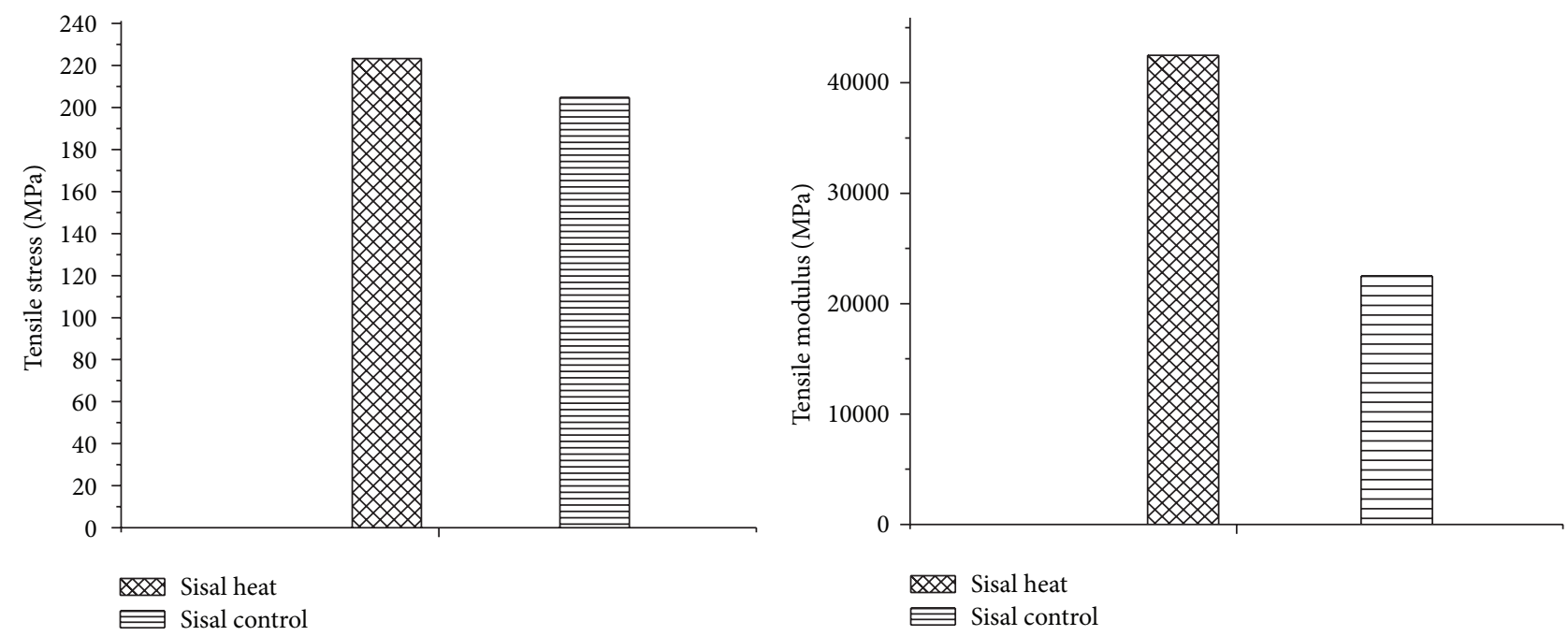

(a)
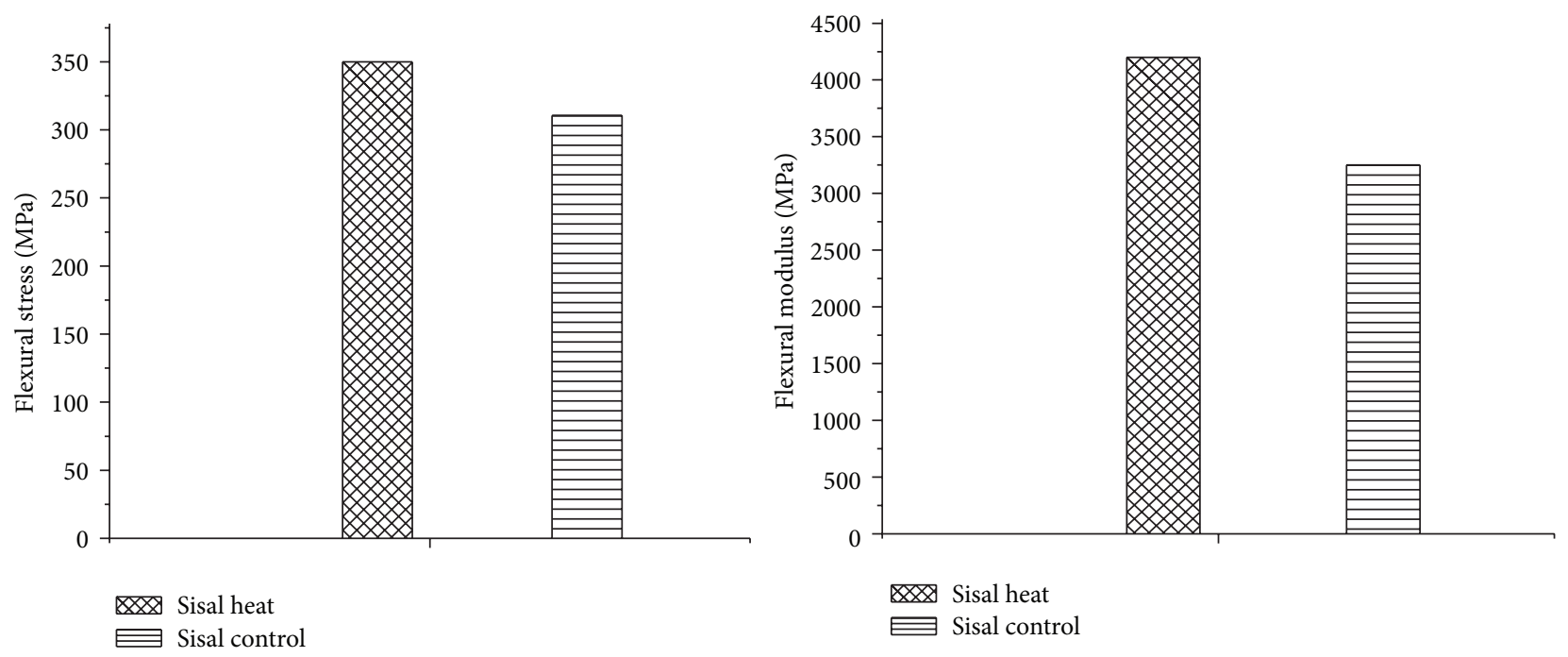

(b)

FIGURE 7: (a) Comparison of tensile behaviour of thermally conditioned and control woven sisal FRP composite, (b) Comparison of flexural behaviour of thermally conditioned and control woven sisal FRP composite.

sets of beams, that is, Groups A, B, and C were all tested for their ultimate shear strengths, in order to evaluate the shear capacity. The beams in Group A, ConS1, and ConS2 (2 number of sample models) were taken as the control beams. It was observed that the beams ConS1 and ConS2 had less load carrying capacity when compared to that of the fully strengthened beams as well as partially strengthened beams, that is, groups B and C beams, respectively. The second set of beams in Group B, which were strengthened by $90^{\circ}$ fully wrapped FRP in single layer by woven sisal FRP, are the ones which displayed the highest shear strength, whereas the last set of beams in Group C, which were strengthened by $90^{\circ}$ strip wrapped woven sisal FRP in single layer are the ones which has shown ultimate strength higher than the control specimens. The first set of beams that is group A, ConS1, and ConS2, failed in shear which proved that the beams were deficient in shear, and also that shear failure occurred before flexural failure. A large number of inclined cracks, which were $45^{\circ}$ inclined to the horizontal reference of the beams developed from near the support region extending in $45^{\circ}$ angles towards the load, that is, towards the upper face of the beam. So, it can be concluded that pure shear cracks developed at the lower face that is the bottom of the beam and extended from the bottom towards the top face of the beam at inclined $45^{\circ}$ angles. Both the beams ConS1 and ConS2 failed in similar manner and Figure 8(a) depicts the clear representation of the failure of group A beams. The average shear strength of group A beams was $90 \mathrm{KN}$. In the second set of beams in group B, models SS1 and SS2 (2 number of sample models), it was seen that both these beams failed in the shear 


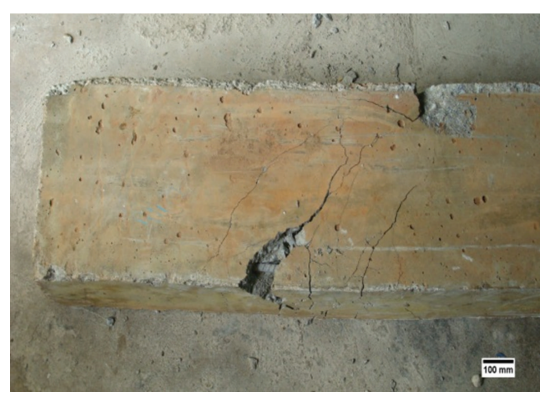

(a)

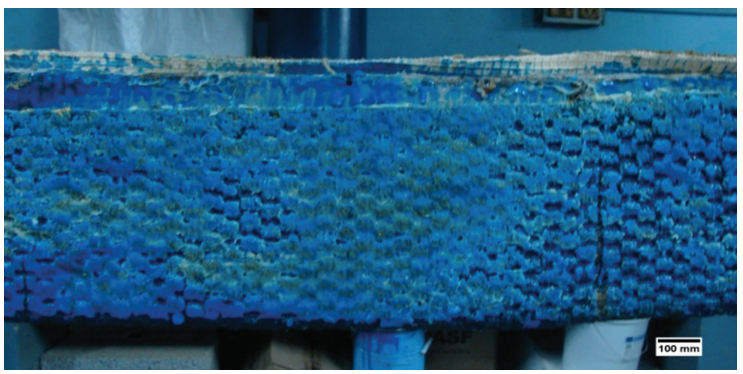

(c)

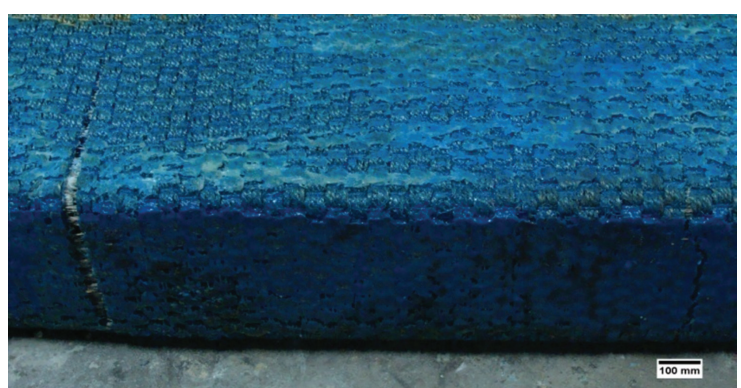

(b)

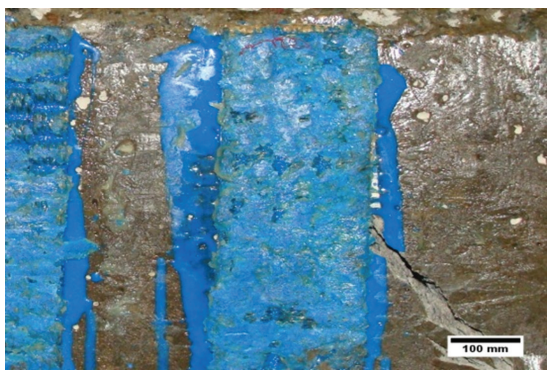

(d)

FIGURE 8: (a) fracture crack of beam ConS1; (b) fracture crack in the left and right shear zone of beam SS1; (c) fracture crack in the left and right shear zone of beam SS2; (d) fracture crack in the shear zone, and no crack in FRP, in beam SS3.

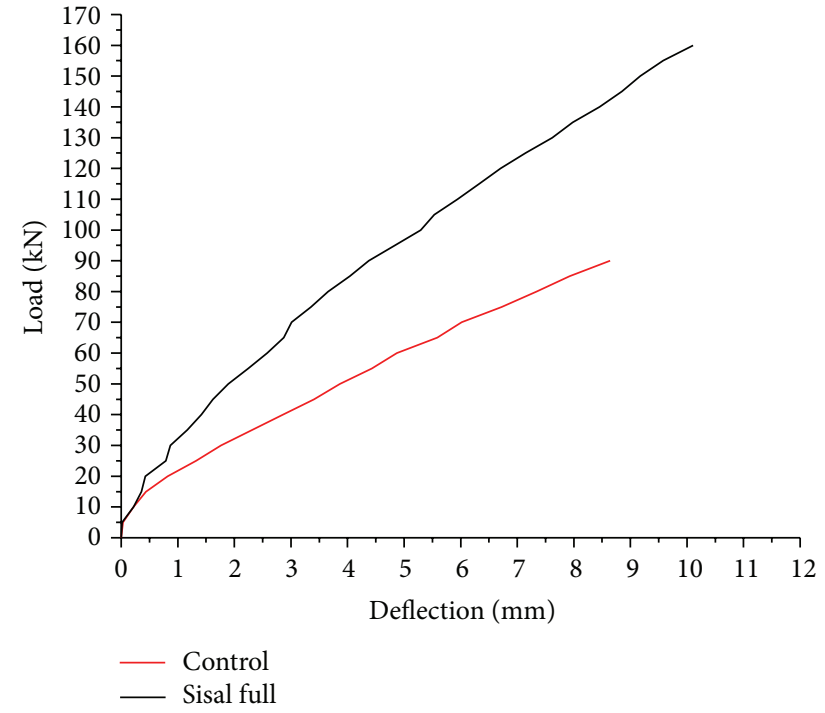

(a)

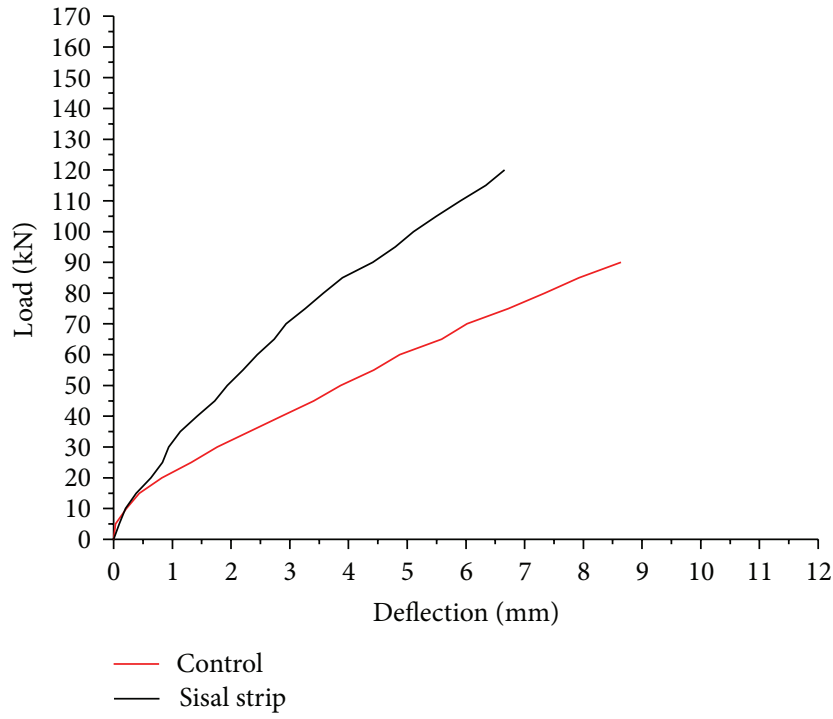

(b)

Figure 9: (a) load versus average midspan deflection of Groups A and B beams; (b) load versus average midspan deflection of Groups A and C beams.

regions, with the development of single crack in the woven sisal FRP, and their shear strength was much higher than that of Group A beams. When load was applied on SS1 and SS2, then firstly the matrix started cracking, then on further increment of load, the sisal fibers in sisal FRP started to crack, then again on further load increment the cracks in sisal FRP started to widen, with absolutely no de-bonding of FRP at all from any sides of the beam, the vertical crack was in the sisal FRP alone, in the shear zone, that is near the support and then this crack started slowly moving from the bottom face of the beam to the top face. Both of the failure modes depicted by SS1 and SS2 were very ductile in nature, with large deflections. Since, there was no de-bonding of sisal FRP, hence the cracks in the RCC beam itself could not be visualized. The ultimate load carrying capacity was reached by further widening of the single crack without generation of any other alternate cracks on the woven sisal FRP. Hence, in each beam, two numbers of cracks were observed at both the shear regions in beam. 


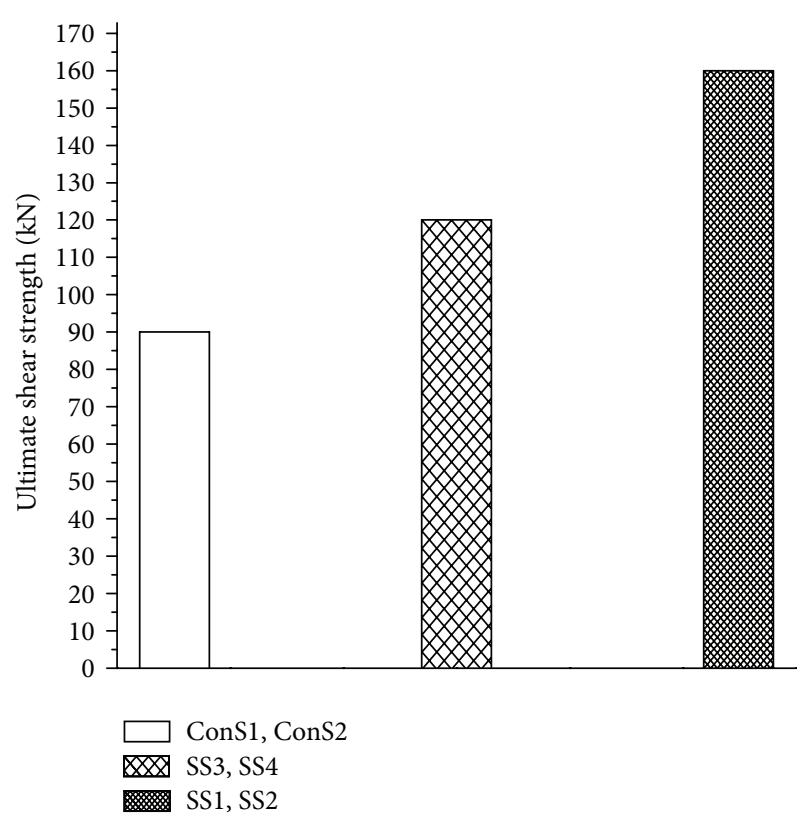

(a)

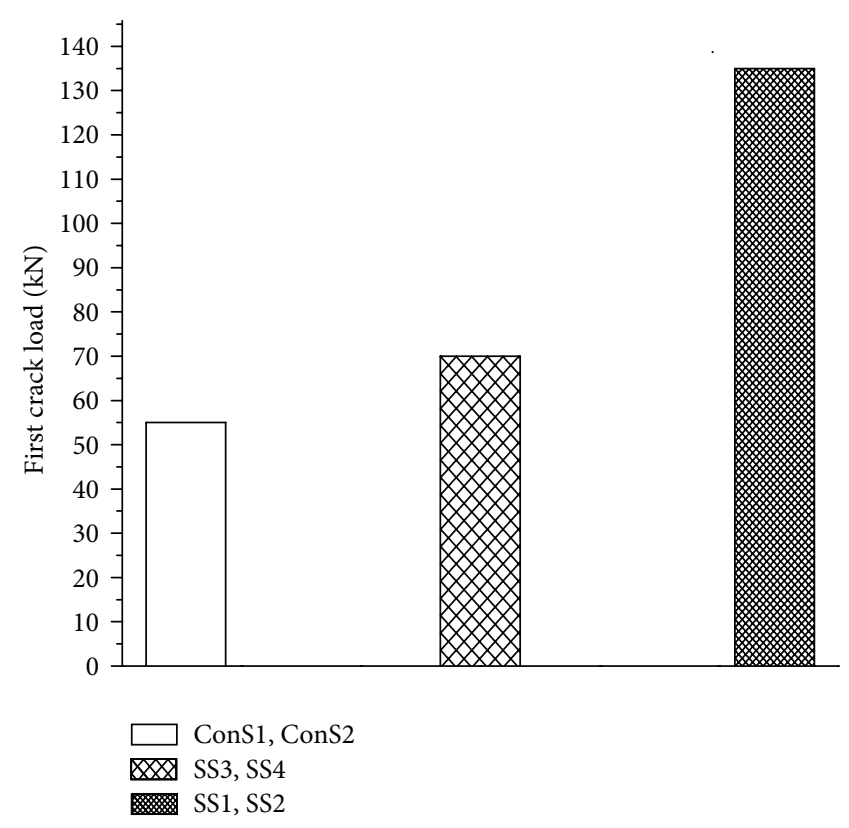

(b)

FIGURE 10: (a) comparison of ultimate shear strength of all beams; (b) comparison of first crack load of all beams.

The average ultimate strength of group B beams SS1 and SS2 was $160 \mathrm{KN}$. Both the beams SS1 and SS2 failed in similar manner and Figures 8(b) and 8(c) depicts the clear representation of the failure mode of these beams. A comparative load versus mid span (average) deflection behavior of group A and B beams is as shown in Figure 9(a). It is very evident that the load deflection behavior of group B beams is much superior, because these beams have higher ultimate load carrying capacity, and also their ultimate deflection of $10.105 \mathrm{~mm}$ is higher than group A beams, which has a ultimate deflection of $8.643 \mathrm{~mm}$, because the ultimate load carrying capacity increases by $77.8 \%$ because of strengthening effect. In the third set of beams, that is group $C$, in which the beams were strengthened by strips of $62 \mathrm{~mm}$ placed at $124 \mathrm{~mm} \mathrm{C/C}$ (at a clear gap of $62 \mathrm{~mm}$, so as to achieve 50\% area FRP strengthening, and leaving a clear edge length of $49 \mathrm{~mm}$ at the supports), it was seen that both the beams SS3, SS4, displayed that their ultimate load carrying capacity was higher than that of Group A beams, but lower than that of group B beams. It was observed for group $\mathrm{C}$ beams, that cracks first developed in the RCC beams and not on the sisal FRP, this indicated that the presence of bonded natural FRP on RCC beams, be it a woven natural FRP like woven sisal, imparts additional strength to the beams, and there by enhances their shear strength. When load was applied on SS3, SS4, then inclined cracks, which were $45^{\circ}$ inclined to the horizontal reference of the beams developed near the support region extending in $45^{\circ}$ angles from the supports towards the load that is, towards the upper face of the beam, but the interesting facet was that a single shear crack did not develop on the sisal FRP nor did the FRP undergo rupture of any nature or even de-bonding. On further increase in the load, large number of inclined cracks, described as above, developed, but again none of the cracks continued through the sisal FRP, this generation of shear cracks in the shear region and its increase in number and length only was restricted to the unbounded RCC beam area. The strip wrapping technique of FRP strengthening increased the ultimate load carrying capacity up to a point which lied between the load carrying capacity of fully wrapped beams and that of control beams. All the failure modes of group $\mathrm{C}$ beams are depicted in Figure $8(\mathrm{~d})$, respectively, which clearly shows the shear cracks in all these beams. The average ultimate strength of group C beams SS3, SS4 was $120 \mathrm{KN}$. A comparative load versus mid span (average) deflection behavior of group A and C beams is as shown in Figure 9(b). It is very evident that the load deflection behavior of group $\mathrm{C}$ beams is much superior than group $\mathrm{A}$ beams, and lies somewhere in between group $A$ and $B$ beams. Beams in group $C$ have higher ultimate load carrying capacity than group A beams, and their ultimate deflection $6.656 \mathrm{~mm}$ is lower than group A beams, which has an ultimate deflection of $8.643 \mathrm{~mm}$, because there is only $33.4 \%$ increase in the load carrying capacity, whereas the effect of full wrapping increases the load carrying capacity by double the amount $(77.8 \%)$.

\section{Conclusions}

(1) The performance of thermally conditioned woven sisal fiber reinforced polymer (FRP) composites was superior to the untreated or raw woven sisal fiber reinforced composites.

(2) The tensile test showed that thermally conditioned woven sisal FRP composite had higher tensile strength value of $223 \mathrm{~N} / \mathrm{mm}^{2}$ as compared untreated 
or raw woven sisal fiber reinforced composites, which had a tensile strength value of $205 \mathrm{~N} / \mathrm{mm}^{2}$.

(3) The flexural test also showed that thermally conditioned woven sisal FRP composite had higher flexural strength value of $350 \mathrm{~N} / \mathrm{mm}^{2}$ as compared to untreated or raw woven sisal fiber reinforced composites, which had a flexural strength value of $311 \mathrm{~N} / \mathrm{mm}^{2}$.

(4) The treatment of thermal conditioning aided in enhancing the mechanical properties of woven sisal fiber reinforced polymer composites by the virtue of modification of cellulosic structure by enhanced cross-linking, increased amount of crystallinity in the fibers, and by de-moisturization, which improved the adhesion between the fibers and the natural rubber backing of the fabric.

(5) The study showed that the reinforcement of woven sisal fiber reinforced polymer composites created a new alternate material with properties that are generally with superior mechanical properties.

(6) When the thermally treated woven sisal fiber reinforced polymer composites were used for strengthening of reinforced concrete beams, then it resulted in significantly increasing the first crack load and the ultimate load carrying capacity of the strengthened beams, when strengthened using both full wrapping and strip wrapping techniques as compared to that of control beams, indicating the reinforcing effect of the woven sisal FRP composite. The maximum increase in the ultimate load carrying capacity by full wrapping technique was $77.8 \%$ and by strip wrapping technique was $33.4 \%$. The presence of natural FRP bonded on the beam inhibited the development of the cracks, and delayed the formation of cracks.

(7) As the degree of strengthening increased, in view of full wrapping and strip wrapping, the load carrying capacity increased with an improvement in the load deflection behavior. Even at higher loads, the woven sisal FRP did not undergo any delamination or rupture and displayed ductile type of failure with huge deflections in the reinforced concrete beam at such high loads. Control beams failed at $90 \mathrm{KN}$, where as the beams strengthened by using thermally treated woven sisal FRP, by full wrapping technique failed at $160 \mathrm{KN}$ and lastly the beams strengthened by using thermally treated woven sisal FRP, by strip wrapping technique failed at $120 \mathrm{KN}$, this depicted the effect of shear strengthening, provided by the use of natural woven sisal FRP, bonded to reinforced concrete beams.

(8) All strengthened beams failed by failure of inside steel, at their corresponding ultimate load and they were also marked by huge deflections in the beams. The presence of bonded sisal FRP totally avoided any catastrophic failure of reinforced concrete beams, by concrete crushing or by FRP delamination.
(9) The cracks at ultimate load of strengthened beams by strip wrapping, were more in number compared to cracks in the control beams, indicating clearly the composite action due to bonded woven sisal FRP composite. The cracks at ultimate load of strengthened beams by full wrapping technique, could not be visualized, since the woven sisal FRP remained bonded to the beam even at failure.

(10) The use of natural woven sisal FRP was very effective in the case of shear strengthening of reinforced concrete beams. The ultimate shear strength of all the strengthened beams increased with the increasing width of the FRP, as strip wrapping showed lesser load carrying capacity than full wrapping.

\section{Acknowledgments}

The authors acknowledge the support extended to the work by various undergraduate and postgraduate students working under the guidance of the authors and also the laboratory supporting staff members and the laboratory assistants.

\section{References}

[1] K.-T. Lau and L.-M. Zhou, "Mechanical performance of composite-strengthened concrete structures," Composites B, vol. 32, no. 1, pp. 21-31, 2001.

[2] S. A. Sheikh, "Performance of concrete structures retrofitted with fibre reinforced polymers," Engineering Structures, vol. 24, no. 7, pp. 869-879, 2002.

[3] R. Al-Amery and R. Al-Mahaidi, "Coupled flexural-shear retrofitting of RC beams using CFRP straps," Composite Structures, vol. 75, no. 1-4, pp. 457-464, 2006.

[4] F. Ceroni, "Experimental performances of RC beams strengthened with FRP materials," Construction and Building Materials, vol. 24, no. 9, pp. 1547-1559, 2010.

[5] J. Dong, Q. Wang, and Z. Guan, "Structural behaviour of RC beams with external flexural and flexural-shear strengthening by FRP sheets," Composites B, vol. 44, pp. 604-612, 2013.

[6] J. A. O. Barros, S. J. E. Dias, and J. L. T. Lima, "Efficacy of CFRPbased techniques for the flexural and shear strengthening of concrete beams," Cement and Concrete Composites, vol. 29, no. 3, pp. 203-217, 2007.

[7] A. A. El-Ghandour, "Experimental and analytical investigation of CFRP flexural and shear strengthening efficiencies of RC beams," Construction and Building Materials, vol. 25, no. 3, pp. 1419-1429, 2011.

[8] M. R. Esfahani, M. R. Kianoush, and A. R. Tajari, "Flexural behaviour of reinforced concrete beams strengthened by CFRP sheets," Engineering Structures, vol. 29, no. 10, pp. 2428-2444, 2007.

[9] R. Al-Rousan and M. Issa, "Fatigue performance of reinforced concrete beams strengthened with CFRP sheets," Construction and Building Materials, vol. 25, no. 8, pp. 3520-3529, 2011.

[10] S. Hashemi and R. Al-Mahaidi, "Flexural performance of CFRP textile-retrofitted RC beams using cement-based adhesives at high temperature," Construction and Building Materials, vol. 28, no. 1, pp. 791-797, 2012. 
[11] J. R. Correia, F. A. Branco, and J. G. Ferreira, "Flexural behaviour of GFRP-concrete hybrid beams with interconnection slip," Composite Structures, vol. 77, no. 1, pp. 66-78, 2007.

[12] T. H. Almusallam, "Load-deflection behavior of RC beams strengthened with GFRP sheets subjected to different environmental conditions," Cement and Concrete Composites, vol. 28, no. 10, pp. 879-889, 2006.

[13] J. R. Correia, L. Valarinho, and F. A. Branco, "Post-cracking strength and ductility of glass-GFRP composite beams," Composite Structures, vol. 93, no. 9, pp. 2299-2309, 2011.

[14] N. F. Grace, W. F. Ragheb, and G. Abdel-Sayed, "Development and application of innovative triaxially braided ductile FRP fabric for strengthening concrete beams," Composite Structures, vol. 64, no. 3-4, pp. 521-530, 2004.

[15] J. Sim, C. Park, and D. Y. Moon, "Characteristics of basalt fiber as a strengthening material for concrete structures," Composites $B$, vol. 36, no. 6-7, pp. 504-512, 2005.

[16] H. S. Kim and Y. S. Shin, "Flexural behavior of reinforced concrete (RC) beams retrofitted with hybrid fiber reinforced polymers (FRPs) under sustaining loads," Composite Structures, vol. 93, no. 2, pp. 802-811, 2011.

[17] A. Peled and A. Bentur, "Geometrical characteristics and efficiency of textile fabrics for reinforcing cement composites," Cement and Concrete Research, vol. 30, no. 5, pp. 781-790, 2000.

[18] Y. Li, Y.-W. Mai, and L. Ye, "Sisal fibre and its composites: a review of recent developments," Composites Science and Technology, vol. 60, no. 11, pp. 2037-2055, 2000.

[19] S. V. Joshi, L. T. Drzal, A. K. Mohanty, and S. Arora, "Are natural fiber composites environmentally superior to glass fiber reinforced composites?" Composites A, vol. 35, no. 3, pp. 371376, 2004.

[20] A. V. Ratna Prasad and K. Mohana Rao, "Mechanical properties of natural fibre reinforced polyester composites: jowar, sisal and bamboo," Materials and Design, vol. 32, no. 8-9, pp. 4658-4663, 2011.

[21] A. C. Milanese, M. O. H. Cioffi, and H. J. C. Voorwald, "Mechanical behavior of natural fiber composites," Procedia Engineering, vol. 10, pp. 2022-2027, 2011.

[22] G. Hota and R. Liang, "Advanced fiber reinforced polymer composites for sustainable civil infrastructures," in Proceedings of the International Symposium on Innovation \& Sustainability of Structures in Civil Engineering, Xiamen University, Nanjing, China, 2011.

[23] K. Begum and M. A. Islam, "Natural fiber as a substitute to synthetic fiber in polymer composites: a review," Research Journal of Engineering Sciences, vol. 2, no. 3, pp. 46-53, 2013.

[24] Laney and M. Langford, Sustainable composites from natural materials [M.S. thesis], North Carolina State University, 2011.

[25] G. Cristaldi, A. Latteri, G. Recca, and G. Cicala, "Composites based on natural fibre fabrics," in Woven Fabric Engineering, chapter 17, InTechOpen, 2010, http://www.intechopen.com/.

[26] M. M. Kabir, H. Wang, T. Aravinthan, F. Cardona, and K. T. Lau, "Effects of natural fibre surface on composite properties: a review," in Proceedings of the 1st International Postgraduate Conference on Engineering, Designing and Developing the Built Environment for Sustainable Wellbeing (eddBE '11), pp. 94-99, 2011.

[27] M. J. John and S. Thomas, "Biofibres and biocomposites," Carbohydrate Polymers, vol. 71, no. 3, pp. 343-364, 2008.

[28] P. D. Dubrovski, Ed., Woven Fabric Engineering, Sciyo, Rijeka, Croatia, 2010.
[29] Textile Biocomposites, Shodhganga, http://shodhganga.inflibnet.ac.in/bitstream/10603/509/12/12_part_3.pdf.

[30] M. Z. Rong, M. Q. Zhang, Y. Liu, G. C. Yang, and H. M. Zeng, "The effect of fiber treatment on the mechanical properties of unidirectional sisal-reinforced epoxy composites," Composites Science and Technology, vol. 61, no. 10, pp. 1437-1447, 2001.

[31] M. Ramesh, K. Palanikumar, and K. Hemachandra Reddy, "Mechanical property evaluation of sisal-jute-glass fiber reinforced polyester composites," Composites B, vol. 48, pp. 1-9, 2013.

[32] A. Campos, J. M. Marconcini, S. M. Martins-Franchetti, and L. H. C. Mattoso, "The influence of UV-C irradiation on the properties of thermoplastic starch and polycaprolactone biocomposite with sisal bleached fibers," Polymer Degradation and Stability, vol. 97, no. 10, 2012.

[33] P. A. Sreekumar, S. P. Thomas, J. M. Saiter, K. Joseph, G. Unnikrishnan, and S. Thomas, "Effect of fiber surface modification on the mechanical and water absorption characteristics of sisal/polyester composites fabricated by resin transfer molding," Composites A, vol. 40, no. 11, pp. 1777-1784, 2009.

[34] S. Kaewkuk, W. Sutapun, and K. Jarukumjorn, "Effect of heat treated sisal fiber on physical properties of polypropylene composites," Advanced Materials Research, vol. 123-125, pp. 1123-1126, 2010. 

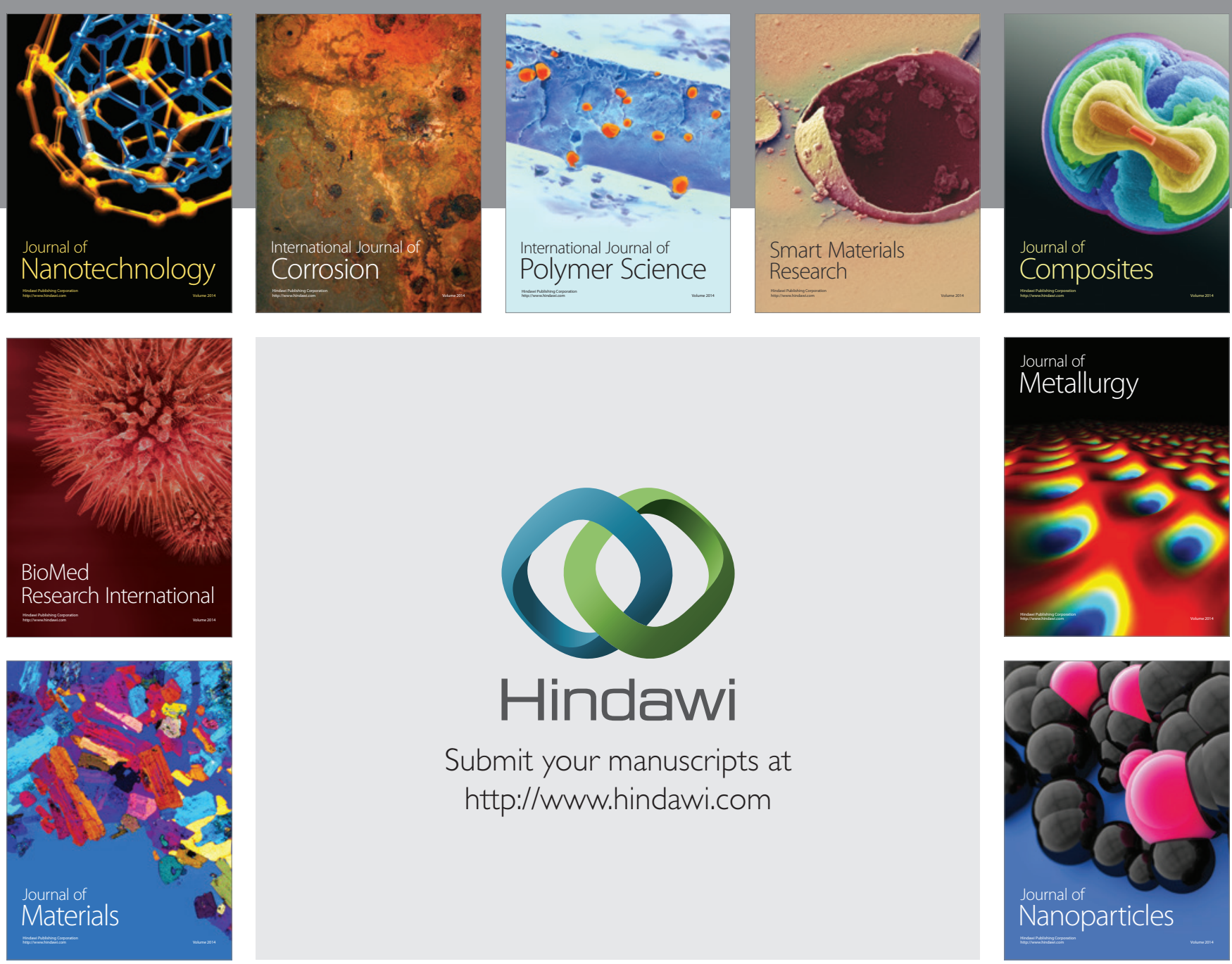

Submit your manuscripts at http://www.hindawi.com
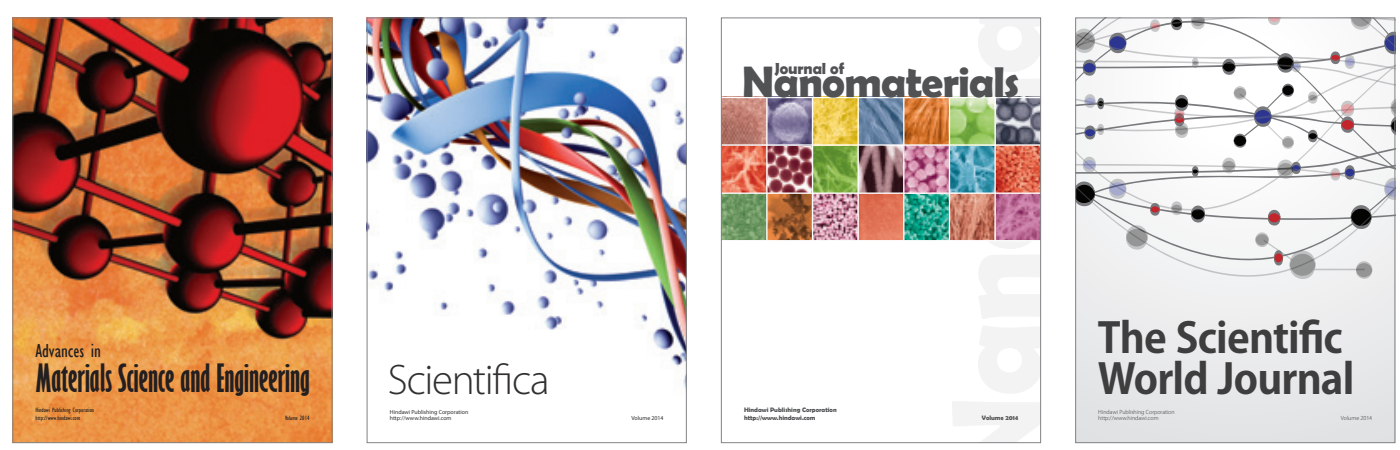

\section{The Scientific World Journal}
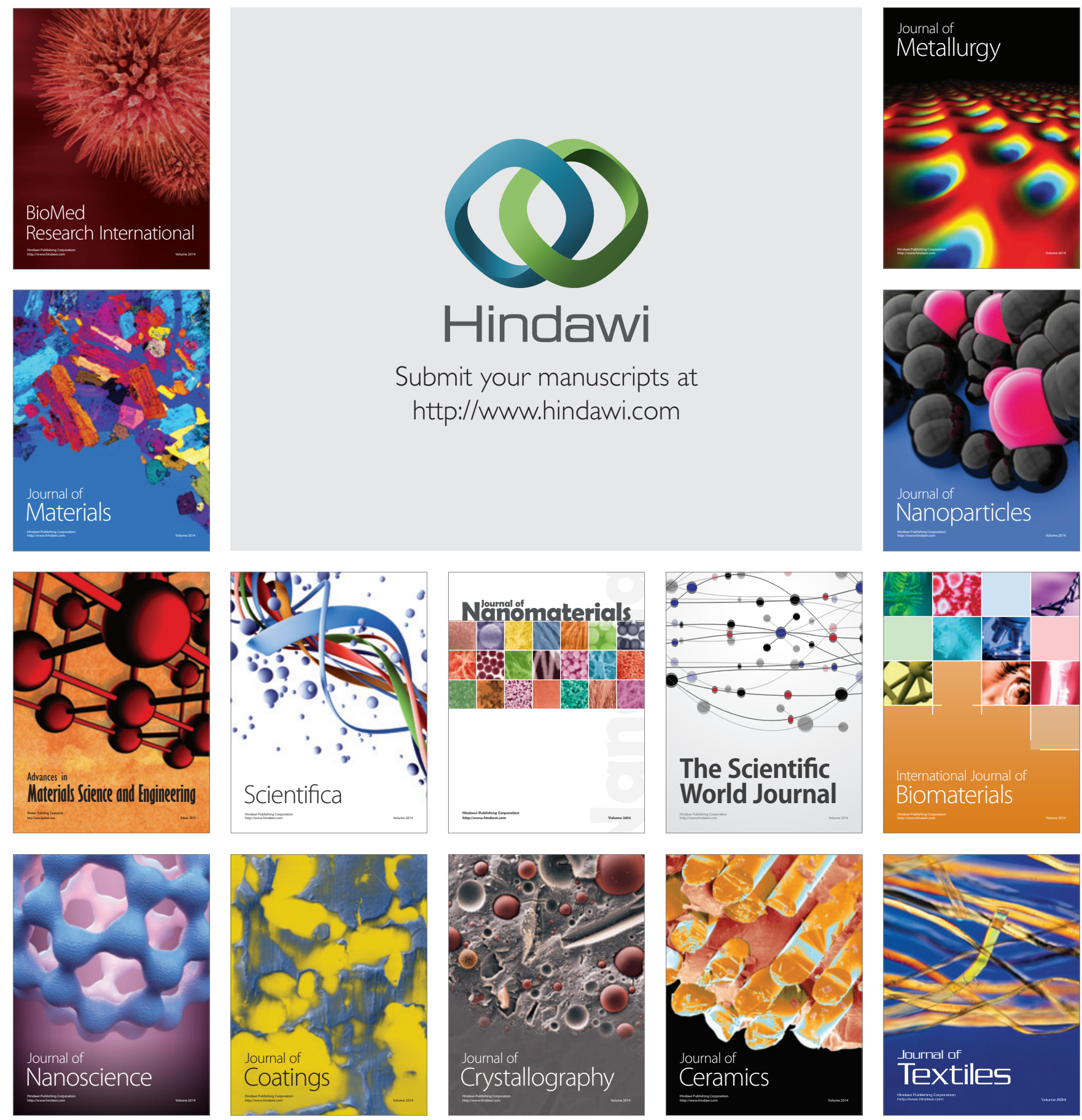